\title{
Dairy calcium intake modifies responsiveness of fat metabolism and blood lipids to a high-fat diet
}

\author{
Janne K. Lorenzen and Arne Astrup* \\ Department of Human Nutrition, Centre for Advanced Food Studies, Faculty of Life Sciences, University of Copenhagen, \\ Rolighedsvej 30, DK-1958 Frederiksberg C, Denmark
}

(Received 12 May 2010 - Revised 12 November 2010 - Accepted 15 November 2010 - First published online 31 January 2011)

\section{Abstract}

Intervention studies have demonstrated that saturated fat increases total and LDL-cholesterol concentrations, and it is therefore recommended that the intake of high-fat dairy products be limited. However, observational studies have found an inverse relationship between the intake of dairy products and incidence of CVD. We aimed to study whether the Ca content of dairy products influences the effect of dairy fat on the lipid profile. The study had a randomised cross-over design. Subjects $(n$ ) were randomised to one of the sequence of four isoenergetic $10 \mathrm{~d}$ diets: low Ca and low fat (LC/LF: approximately $700 \mathrm{mg} \mathrm{Ca} / \mathrm{d}, 25 \%$ of energy (fat); high Ca and LF (HC/LF: approximately $2800 \mathrm{mg} \mathrm{Ca} / \mathrm{d}, 25 \%$ of energy fat); LC and high fat (LC/HF: approximately $700 \mathrm{mg} \mathrm{Ca} / \mathrm{d}$, $49 \mathrm{E} \% \mathrm{fat}$ ); or $\mathrm{HC}$ and HF (approximately $2800 \mathrm{mg} \mathrm{Ca} / \mathrm{d}, 49 \mathrm{E} \%$ fat). Blood variables were measured before and after each diet period, and faeces and urine were collected at the end of each diet period. A two-way ANOVA was used to examine the effect of Ca and fat intake. Independent of $\mathrm{Ca}$ intake, the HF diet increased the concentrations of total $(9 \% ; P<0 \cdot 0001)$, LDL $(14 \% ; P<0 \cdot 0001)$ - and HDL (13\%; $P=0 \cdot 0002)$-cholesterol compared with the LF diet. However, independent of fat intake, the HC diet decreased the concentrations of total $(4 \% ; P=0 \cdot 0051)$ and LDL-cholesterol $(10 \% ; P<0.0001)$ but not HDL-cholesterol compared with the LC diet. In addition, total:HDL-cholesterol was decreased ( $5 \% ; P=0.0299)$, and HDL:LDL was increased $(12 \% ; P=0.0097)$ by the HC diet compared with the LC diet. Faecal fat excretion was increased by both the HC $(P<0.0001)$ and HF $(P=0.0052)$ diets. In conclusion, we observed that dairy Ca seems to partly counteract the raising effect of dairy fat on total and LDL-cholesterol, without reducing HDL-cholesterol.

\section{Key words: Dairy products: Calcium: Blood lipids: LDL: Faecal fat excretion}

Observational studies have found that dairy consumption is inversely associated with the metabolic syndrome ${ }^{(1,2)}$. The metabolic syndrome is a cluster of risk factors, including dyslipidaemia, insulin resistance, increased blood pressure and abdominal obesity, that together markedly increase the risk of diabetes and CVD. One of the components in dairy products, which has been associated with this reduced risk, is $\mathrm{Ca}$.

The effect of a high $\mathrm{Ca}$ intake on energy balance has attracted considerable attention. Several observational studies have found inverse associations between intake of $\mathrm{Ca}$ or dairy products and body weight, body fat and abdominal obesity $^{(1,3-11)}$. In support of this, intervention studies have shown that $\mathrm{Ca}$, especially dairy $\mathrm{Ca}$, produces decreases in body weight and body fat ${ }^{(4,12-16)}$. However, others have failed to find an effect on body fatness ${ }^{(8,17-20)}$. We have recently shown that one of the mechanisms by which dairy Ca affects energy balance, and potentially body weight, is via an increased faecal fat and energy excretion ${ }^{(21,22)}$.
Others have shown that supplementary Ca produces increased faecal fat excretion ${ }^{(23)}$. Some found that this was mainly due to an increased excretion of SFA ${ }^{(24-26)}$, but others did not ${ }^{(21)}$.

SFA, especially palmitic acid, are the dietary component considered most responsible for increases in serum cholesterol concentrations ${ }^{(27)}$. The increase occurs primarily in the LDL-cholesterol fraction, and it is well known that a high concentration of LDL-cholesterol is one of the strongest predictors of increased risk of CVD. The mechanism by which SFA increase LDL is not completely understood, but it has been suggested that it may be via suppression of LDL-receptor-mediated clearance of $\mathrm{LDL}^{(27)}$. Dairy products have a high content of SFA and cholesterol, and it has therefore been a general perception that fatty dairy products are associated with a risk of CVD. However, evidence from observational studies indicates that milk or dairy consumption is inversely related to incidence of $\mathrm{CVD}^{(28)}$. Furthermore, several studies have indicated that milk and other dairy products may not affect the lipid profile as adversely, as would otherwise

Abbreviations: HC, high Ca; HF, high fat; LC, low Ca; LF, low fat.

*Corresponding author: Professor A. Astrup, fax +453533 2483, email ast@life.ku.dk 
be predicted from their fat content and composition (reviewed in Pfeuffer \& Schrezenmeir ${ }^{(29)}$, Tholstrup ${ }^{(30)}$, Nestel ${ }^{(31)}$ ). Dietary Ca intake has been observed to be inversely related to total and LDL-cholesterol concentrations ${ }^{(5)}$. However, the results from intervention studies examining the effect of Ca (dairy or supplementary) on the lipid profile are inconsistent $^{(14,19,24,25,32-36)}$. Thus, there is a need for more studies that explore the potential role of $\mathrm{Ca}$ intake in lipid metabolism.

The aim of the present study was to examine whether a concomitant intake of the $\mathrm{Ca}$ content of dairy products modifies the effect of dairy fat on the lipid profile.

\section{Experimental work}

\section{Subjects}

A total of fifteen male subjects were recruited through advertising in newspapers, on the Internet, and at universities and student halls of residence in Copenhagen. The subjects were healthy, with a mean age of $32 \cdot 8$ (SEM 1.2 ) years and a mean BMI of $28 \cdot 1$ (SEM $0 \cdot 6) \mathrm{kg} / \mathrm{m}^{2}$. The exclusion criteria were smoking, lactose intolerance, infections or metabolic diseases and the use of dietary supplements. The study was carried out at the Department of Human Nutrition, Faculty of Life Sciences, Frederiksberg, Denmark. The study was conducted according to the guidelines laid down in the Declaration of Helsinki, and all procedures involving human subjects were approved by the Municipal Ethical Committee of Copenhagen and Frederiksberg (KF 01-144/02). Written informed consent was obtained from all subjects. The study was registered at ClinicalTrails.gov (NCT00519909). Subjects received 6000 DKK (approximately $\$ 1000)$ on completion of all tests.

\section{Design}

The study had a randomised, cross-over design, with four intervention periods of $10 \mathrm{~d}$ with controlled intake of four different isoenergetic diets. The subjects were randomised by draws to the sequence of the four diets. Between each diet period, there was a washout period of at least 1 week, where the subjects consumed their habitual diets. Due to the design, it was not possible to make the study blinded for the subjects. The study was therefore only blinded for the staff collecting, handling and analysing the blood, faeces and urine samples.

\section{Diet}

The four different diets contained low $\mathrm{Ca}$ and high fat (LC/HF), high $\mathrm{Ca}$ and high fat $(\mathrm{HC} / \mathrm{HF})$, low $\mathrm{Ca}$ and low fat (LC/LF), or high Ca and low fat (HC/LF) (Table 1). The computer database of foods from the National Food Agency of Denmark (Dankost 3000; National Food Agency of Denmark, Søborg, Denmark) was used to calculate the content of microand macronutrients. The main source of Ca was dairy products, and the main difference in dietary fat between the LF and HF diets was dairy fat (approximately 90\%). During the HC diet periods, the subjects were given milk with every
Table 1. Nutrient composition of the four diets*

\begin{tabular}{lcccc}
\hline & LC/HF & HC/HF & LC/LF & HC/LF \\
\hline Energy (MJ) & $10 \cdot 00$ & $10 \cdot 00$ & $10 \cdot 15$ & $10 \cdot 18$ \\
Protein (E\%) & $15 \cdot 0$ & $15 \cdot 0$ & $15 \cdot 5$ & 15.5 \\
Protein (g/10 MJ) & 89 & 90 & 91 & 91 \\
Carbohydrate (E\%) & $35 \cdot 6$ & $35 \cdot 5$ & 59.6 & 59.5 \\
Carbohydrate (g/10 MJ) & 212 & 213 & 350 & 350 \\
Fat (E\%) & 49.5 & 49.5 & $25 \cdot 0$ & 25.0 \\
Fat (g/10 MJ) & 132 & 132 & 66 & 66 \\
Dairy fat (g/10 MJ) & 98 & 98 & 37 & 38 \\
SFA (\% of total fat) & 59 & 60 & 54 & 54 \\
MUFA (\% of total fat) & 34 & 33 & 35 & 35 \\
PUFA (\% of total fat) & 8 & 8 & 11 & 11 \\
Ca (mg/10 MJ) & 474 & 1971 & 504 & 1977 \\
Phosphate (mg/10 MJ) & 837 & 2050 & 815 & 1996 \\
Fibre (g/10 MJ) & 13.5 & 13.5 & 15.1 & 15.3 \\
Vitamin D (mg/10 MJ) & 1.6 & 2.7 & 1.0 & 2.0 \\
\hline
\end{tabular}

$\mathrm{LC} / \mathrm{HF}$, low $\mathrm{Ca}$ and high fat; $\mathrm{HC} / \mathrm{HF}$, high $\mathrm{Ca}$ and high fat; LC/LF, low $\mathrm{Ca}$ and low fat; $\mathrm{HC} / \mathrm{LF}$, high $\mathrm{Ca}$ and low fat; $\mathrm{E} \%$, percentage of energy.

* Each diet was composed of three different breakfast, lunch and dinner dishes, and three different snacks, which were served on alternate days. The diets were adjusted according to the subjects individual energy requirement.

meal to increase their $\mathrm{Ca}$ intake (Table 1). During the LC diet periods, they were given a protein drink containing whey powder (Lacprodan ${ }^{\circledR}$ DI-9224; Arla Foods Ingredients AmbA, Viby, Denmark), casein powder (Miprodan ${ }^{\circledR}$ 30; Arla Foods Ingredients AmbA) and lactose (Arla Foods Ingredients AmbA). Thus, all diets had the same content of whey, casein and lactose. In addition, the diets were adjusted so that the LF and HF diets had the same quantity of dairy fat and the same fatty acid composition (Table 1). The energy content of the LF and HF diets was equated by increasing the intake of carbohydrate-rich foods (mainly refined carbohydrates: white bread, potatoes, rice, jam, sugar and juice) during the LF diet periods to minimise changes in fibre intake. Each diet was composed of three different breakfast, lunch and dinner dishes, and three different snacks, which were served on alternate days. The aim was that the only difference between the four diets should be the amount of dairy $\mathrm{Ca}$ and dairy fat. The diets were prepared at the department according to each subject's individual energy requirement and adjusted to the nearest $1 \mathrm{MJ}$. The energy requirement of each subject was calculated as BMR $\times$ physical activity level. BMR was estimated using the following equation ${ }^{(37)}$ :

$$
\mathrm{BMR}=0 \cdot 102 \times \mathrm{FFM}+0 \cdot 024 \times \mathrm{FM}+0 \cdot 85 .
$$

Body composition was measured at baseline by the bioelectrical impedance method, and fat-free mass (FFM) and fat mass (FM) were calculated (Animeter; Unitech, Hobro, Denmark). The subjects' basic physical activity level value were set to $1 \cdot 6-2 \cdot 0$, which was estimated on the basis of their main occupation ${ }^{(38)}$. If subjects reported participating in sports in their spare time, their physical activity level value was increased according to the type of physical activity and the average hours spent weekly on the activity ${ }^{(39)}$. The mean energy requirement of the subjects who completed the study was $14 \mathrm{MJ} / \mathrm{d}$.

On weekdays, breakfast was consumed at the department, whereas lunch, snacks and dinner were given to the subjects 
to eat at home. All meals for the weekends were supplied to the subjects to consume at home. The subjects were instructed to adhere strictly to the supplied diet and not to mix the different meals, and to report any deviation from the diet plan. In addition, they were instructed to divide the supplied milk into four portions and consume the same amount with each meal/snack. In addition to the meals, the subjects were supplied with water with a low content of $\mathrm{Ca}(12 \mathrm{mg} / \mathrm{l})$, which they were allowed to drink ad libitum. They were allowed to make tea and coffee with this water. The subjects were instructed to register their intake, and no significant differences in water intake between the diet periods were found.

\section{Anthropometrics and body composition}

Height was ascertained at baseline to the nearest centimetre using a Seca stadiometer (Hultafors AB, Hultafors, Sweden). Weight was measured at baseline and before and after each diet period. The subjects were fasting on all occasions. Weight was measured in $\mathrm{kg}$ with one decimal on a Lindeltronic 8000 scale (Samhall Lavi AB, Kristianstad, Sweden).

\section{Laboratory analyses}

Blood samples. Venous blood samples were drawn on the morning of the first day of every diet period and on the morning after the last day of every diet period. The subjects had fasted overnight. Blood samples for plasma analyses were collected in tubes containing EDTA and placed on ice immediately. Blood samples for serum analyses were collected in serum tubes and kept at room temperature for $30 \mathrm{~min}$ to coagulate. All samples were centrifuged at $2800 \boldsymbol{g}$ for $15 \mathrm{~min}$ at $4^{\circ} \mathrm{C}$ and stored at $-20^{\circ} \mathrm{C}$ until later analysis (samples for measurement of LDL-cholesterol were stored at $-80^{\circ} \mathrm{C}$ ).

Serum concentrations of total cholesterol, HDL-cholesterol, NEFA, TAG and insulin. Total cholesterol was measured by an enzymatic photometric test using a Pentra 400 analyser (HORIBA ABX, Montpellier, France). $\mathrm{CV}_{\text {intra }}$ and $\mathrm{CV}_{\text {inter }}$ were 0.9 and $1.6 \%$, respectively. HDL-cholesterol was measured by an enzymatic colorimetric test using a Pentra 400 analyser (HORIBA ABX). $\mathrm{CV}_{\text {intra }}$ and $\mathrm{CV}_{\text {inter }}$ were 1.2 and $4.0 \%$, respectively. LDL-cholesterol was measured by an enzymatic colorimetric test using a Pentra 400 analyser (HORIBA ABX). $\mathrm{CV}_{\text {intra }}$ and $\mathrm{CV}_{\text {inter }}$ were 1.3 and $2.7 \%$, respectively. NEFA was determined by an enzymatic colorimetric method using a Pentra 400 analyser (HORIBA ABX). $\mathrm{CV}_{\text {intra }}$ and $\mathrm{CV}_{\text {inter }}$ were 1.7 and $5.1 \%$, respectively. TAG was measured by an enzymatic photometric test using a Pentra 400 analyser (HORIBA ABX). $\mathrm{CV}_{\text {intra }}$ and $\mathrm{CV}_{\text {inter }}$ were 2.6 and $3.2 \%$, respectively. Insulin was determined by chemiluminescent immunometric assay using an Immulite 1000 analyser (Diagnostic Products Corporation, Los Angeles, CA, USA). $\mathrm{CV}_{\text {intra }}$ and $\mathrm{CV}_{\text {inter }}$ were $2 \cdot 7$ and $7.4 \%$, respectively.

Plasma concentrations of glucose. Glucose was measured by an enzymatic endpoint method (Hexokinase) using a Pentra 400 analyser (HORIBA ABX). $\mathrm{CV}_{\text {intra }}$ and $\mathrm{CV}_{\text {inter }}$ were 0.7 and $2.5 \%$, respectively.
Faeces. All faeces excreted were collected in pre-weighed containers during the last $5 \mathrm{~d}$ of each diet period. In addition, the subjects completed a questionnaire on daily defecation frequency and faeces consistency throughout every diet period. The faecal samples were weighed and frozen at $-20^{\circ} \mathrm{C}$. Before analysis, the samples were freeze-dried and homogenised, and samples from the same diet period were pooled. Faecal energy was obtained using a bomb calorimeter (Ika-calorimeter system C4000; Heitersheim, Germany). Before total fat content was measured, the samples were acid hydrolysed with $3 \mathrm{M}-\mathrm{HCl}$. Total fat content was measured by a method modified after Bligh \& Dyer ${ }^{(40)}$.

Bile acids in faecal samples were quantified by reversedphase HPLC with pulsed amperometric detection as described by others ${ }^{(41,42)}$. The freeze-dried samples $(1 \mathrm{~g})$ were diluted 50 -fold in a mixture containing $20 \%$ acetonitrile, $10 \% \mathrm{NaOH}$ and $70 \%$ water. Ursodeoxycholate (sigma) was added to the mixture as an internal standard at a final concentration of $40 \mu \mathrm{mol} / \mathrm{l}$. The mixture was mixed using a Shaker VXR vibrax (IKA-Werke, Staufen, Germany) at $1500 \mathrm{rpm}$ for $30 \mathrm{~s}$ and subsequently centrifuged at $5000 \boldsymbol{g}$ for $10 \mathrm{~min}$. The supernatant was passed through a nylon syringe filter membrane (Cameo 17N-227DDR02T17NB) before injection onto the HPLC column.

Ca was measured by atomic absorption spectrophotometry using a PYE UNICAM SP9 atomic absorption spectrophotometer (Philips Electron Optics, Mahwah, NJ, USA). Before analysis, the samples were destroyed by dry-ashing at $525^{\circ} \mathrm{C}$ for $6 \mathrm{~h}$, and the ashes were dissolved in acid $\left(6.5 \% \mathrm{HNO}_{3}\right)$. The solution was diluted with a lanthanum chloride solution before $\mathrm{Ca}$ concentration was measured.

Transit time was measured using non-absorbable, radioopaque markers (Medifact, Göteborg, Sweden). On the 4th to the 8th day of each diet period, the subjects consumed a capsule containing twenty markers with breakfast. There were different shaped markers for each day. Transit time was measured as described elsewhere ${ }^{(43)}$. Retrieval of the markers consumed on days 5-7 was also used as a measurement for complete faecal collection. If the retrieval was above $70 \%$, the collection was assumed to be complete.

Urine samples. During the last $24 \mathrm{~h}$ of each diet period, the subjects collected all urine. The urine volume was measured, and the samples were stored at $-20^{\circ} \mathrm{C}$ until further analyses. Urinary $\mathrm{Ca}$ concentration was measured using atomic absorption on a Spectra AA-200 (Varian, Mulgrave, VIC, Australia). $\mathrm{CV}_{\text {intra }}$ and $\mathrm{CV}_{\text {inter }}$ were $2 \cdot 1$ and $2 \cdot 9 \%$, respectively.

\section{Statistical analyses}

All values are expressed as means with their standard errors unless otherwise stated. A two-way ANOVA was used to examine the effect of dairy $\mathrm{Ca}$ intake and dairy fat intake, as well as the interaction between the two (only included when significant), on blood variables and body weight. ANOVA was performed in Proc Mixed. As the study had a cross-over design, subjects were included as a random effect. Values from before the diet period were included as a covariate in 
all analyses. Sequence of the test diets was included as a covariate if it was found to have a significant effect. LSMEANS were used to estimate the adjusted means. Differences in faecal and urinary variables were analysed by two-way ANOVA with subjects included as a random effect. Pair-wise comparisons were performed by a paired $t$ test with Tukey's adjustment. All statistical analyses were performed using the Statistical Analysis Package, SAS ${ }^{\mathcal{C}}$ version 9.1 (SAS Institute, Cary, NC, USA). The level of significance was set at $P<0 \cdot 05$.

\section{Power}

Based on studies performed previously at our department, we have assumed that a study group of twelve subjects should give us $85 \%$ power, sufficient to detect a difference in faecal fat excretion of $4 \mathrm{~g} / \mathrm{d}^{(21,22)}$. Calculating with a dropout rate of $20 \%$, we included fifteen subjects in the study.

\section{Results}

Of the fifteen subjects, nine completed all four diet periods. Reasons for not completing the study were moving address (one subject) and problems with compliance to the protocol (five subjects). Only data from the subjects completing the study were included in the data analyses. The mean total recovery of $\mathrm{Ca}$ (faecal + urine) was above $90 \%$ during all diet periods, indicating a high compliance to the diet. During the $\mathrm{HC} / \mathrm{HF}$ diet periods, one subject had a very low Ca recovery $(<50 \%)$, indicating a very low compliance, and all data from this subject during this diet period were therefore excluded from the statistical analyses. The subjects' habitual Ca intake was 1223 (sem 96) mg/d.

Table 2. Concentration of blood variables in the four different diet periods

\section{Blood variables}

Concentrations of total, LDL- and HDL-cholesterol, TAG, HDL:LDL-cholesterol and total:HDL-cholesterol before and after each diet period are presented in Table 2 .

There was a significant effect of dairy Ca and dairy fat intake on total and LDL-cholesterol concentrations (Fig. 1). Dairy fat but not dairy Ca had a significant effect on HDL-cholesterol. Dairy Ca but not dairy fat had a significant effect on total: HDL-cholesterol and HDL:LDL-cholesterol. There was no significant interaction between dairy $\mathrm{Ca}$ and dairy fat intake on either of the variables (Table 2).

Independent of dairy Ca intake, total, LDL- and HDLcholesterol concentrations increased with increased dairy fat intake. Total, LDL- and HDL-cholesterol concentrations were 9\% (adjusted mean: HF 5.50 (SEm 0.15) v. LF 5.04 (sem 0.15 ) mmol $/ 1 ; P<0.0001$ ), 14\% (adjusted mean: HF 3.52 $(\operatorname{sem} 0 \cdot 15) \mathrm{mmol} / \mathrm{l} v$. LF $3.08(\operatorname{sem} 0 \cdot 15) \mathrm{mmol} / \mathrm{l} ; \quad P<0.0001)$ and $13 \%$ (adjusted mean: HF 1.22 (SEm 0.02) mmol/1 $v$. LF 1.08 (sem 0.02$) \mathrm{mmol} / \mathrm{l} ; \quad P=0.0002$ ) higher after $\mathrm{HF}$ intake compared with LF intake, when adjusted for concentrations before the diet periods. A trend was found for total:HDLcholesterol concentration $(P=0.0575)$.

Independent of dairy fat intake, total and LDL-cholesterol, but not HDL-cholesterol, concentrations were decreased by increased dairy $\mathrm{Ca}$ intake. Total and LDL-cholesterol concentrations were 4\% (adjusted mean: HC 5.16 (SEM 0.15) mmol/1 $v$ LC $5.39(\operatorname{sem} 0 \cdot 15) \mathrm{mmol} / \mathrm{l} ; P=0.0051)$ and $10 \%$ (adjusted mean: HC $3 \cdot 12($ SEM $0 \cdot 16) \mathrm{mmol} / \mathrm{l} v$. LC $3 \cdot 48$ (SEM 0.15) mmol/l; $P<0.0001)$ lower after HC intake compared with LC intake, when adjusted for concentrations before the diet periods. In addition, the concentration of total:HDL-cholesterol was

(Mean values with their standard errors)

\begin{tabular}{|c|c|c|c|c|c|c|c|c|c|c|c|}
\hline & \multicolumn{2}{|c|}{ LC/HF† } & \multicolumn{2}{|c|}{ HC/HF‡ } & \multicolumn{2}{|c|}{$\mathrm{LC} / \mathrm{LF} \dagger$} & \multicolumn{2}{|c|}{$\mathrm{HC} / \mathrm{LF} \dagger$} & \multicolumn{3}{|c|}{ Two-way ANOVA§ } \\
\hline & Mean & SEM & Mean & SEM & Mean & SEM & Mean & SEM & Dairy Ca & Dairy fat & Dairy $\mathrm{Ca} \times$ dairy fat \\
\hline \multicolumn{12}{|c|}{ Total cholesterol (mmol/l) } \\
\hline Before & 5.09 & 0.24 & $5 \cdot 02$ & $0 \cdot 26$ & $5 \cdot 02$ & 0.19 & $5 \cdot 07$ & 0.23 & & & \\
\hline After & $5 \cdot 68^{\star}$ & $0 \cdot 21$ & $5 \cdot 26$ & 0.20 & 5.09 & 0.16 & 4.99 & 0.21 & 0.0051 & $<0.0001$ & - \\
\hline \multicolumn{12}{|c|}{ LDL-cholesterol (mmol/l) } \\
\hline Before & 3.04 & 0.18 & 3.09 & $0 \cdot 20$ & 3.04 & 0.13 & 3.09 & 0.13 & & & \\
\hline After & $3.73^{*}$ & $0 \cdot 21$ & $3 \cdot 31$ & $0 \cdot 20$ & $3 \cdot 17$ & 0.17 & 2.99 & 0.17 & $<0.0001$ & $<0.0001$ & - \\
\hline \multicolumn{12}{|c|}{ HDL-cholesterol (mmol/l) } \\
\hline Before & $1 \cdot 14$ & 0.09 & $1 \cdot 11$ & 0.04 & $1 \cdot 19$ & 0.09 & $1 \cdot 14$ & 0.09 & & & \\
\hline After & $1 \cdot 22$ & 0.06 & $1 \cdot 19$ & 0.06 & $1 \cdot 10^{*}$ & 0.09 & 1.08 & 0.06 & 0.8817 & 0.0002 & - \\
\hline \multicolumn{12}{|c|}{ TAG (mmol/l) } \\
\hline Before & 1.56 & 0.34 & 1.48 & 0.29 & 1.51 & 0.31 & $1 \cdot 74$ & 0.37 & & & \\
\hline After & $1 \cdot 13$ & $0 \cdot 16$ & $1 \cdot 35$ & $0 \cdot 19$ & 1.62 & 0.29 & 1.58 & 0.27 & 0.6874 & 0.0557 & - \\
\hline \multicolumn{12}{|c|}{ HDL:LDL-cholesterol } \\
\hline Before & 0.39 & 0.04 & 0.38 & 0.04 & 0.40 & 0.04 & 0.37 & 0.03 & 0.0025 & 0.5097 & - \\
\hline After & $0.34^{*}$ & 0.03 & 0.37 & 0.04 & $0.36^{*}$ & 0.04 & 0.38 & 0.04 & & & \\
\hline \multicolumn{12}{|c|}{ Total:HDL-cholesterol } \\
\hline Before & $4 \cdot 63$ & 0.38 & $4 \cdot 57$ & 0.32 & $4 \cdot 38$ & 0.31 & $4 \cdot 46$ & 0.33 & 0.0299 & 0.0575 & - \\
\hline After & $4 \cdot 77$ & $0 \cdot 30$ & $4 \cdot 50$ & $0 \cdot 27$ & $4 \cdot 83^{\star}$ & 0.35 & $4 \cdot 76$ & 0.33 & & & \\
\hline
\end{tabular}

LC/HF: low Ca and high fat; HC/HF: high $\mathrm{Ca}$ and high fat; LC/LF: low $\mathrm{Ca}$ and low fat; HC/LF: high Ca and low fat.

Mean values were significantly different from concentration before the diet period: ${ }^{\star} P<0.05$ (paired $t$ test).

$\dagger n 9$.

$\ddagger n 8$.

§ Adjusted for concentration measured before each diet period. 

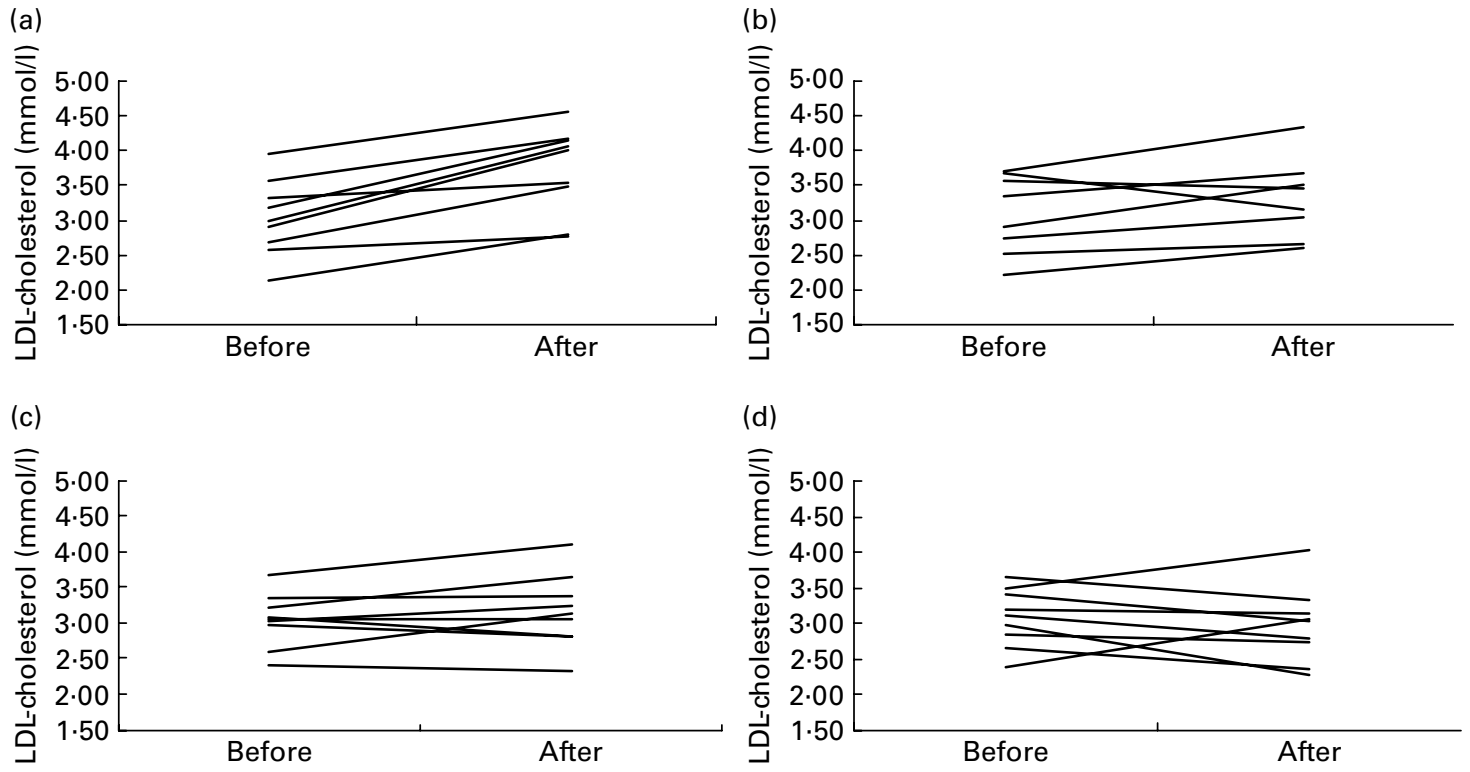

Fig. 1. Individual changes in LDL-cholesterol concentration for each subject from before to after each diet period. (a) Low Ca and high fat; (b) high Ca and high fat; (c) low $\mathrm{Ca}$ and low fat and (d) high $\mathrm{Ca}$ and low fat.

5\% lower (adjusted mean: HC 4.54 (SEM 0.12) v. LC 4.80 (SEM 0.12); $P=0.0299$ ) and of HDL:LDL was $12 \%$ higher (adjusted mean: HC 0.38 (SEm 0.01) v. LC 0.34 (sem 0.01); $P=0.0025)$ after HC intake compared with LC intake.

There was no significant effect of either dairy $\mathrm{Ca}$ intake or dairy fat intake on NEFA, insulin or glucose concentrations after the diet period when adjusted for concentrations before the diet period (data not shown).

\section{Excretion of energy, fat, bile acids and calcium}

Due to a low recovery of transit markers $(<70 \%)$, four faecal collections (from different subjects) were judged incomplete and were therefore excluded.

Urine and faecal excretion of $\mathrm{Ca}$ are presented in Table 3. As expected, dairy $\mathrm{Ca}$ intake had a significant effect on urine and faecal $\mathrm{Ca}$ excretion. Faecal (adjusted mean: HC $2359 \mathrm{mg} / \mathrm{d} v$. LC $537 \mathrm{mg} / \mathrm{d} ; P<0.0001$ ) and urine (adjusted mean: HC $140(\operatorname{sem} 16) \mathrm{mg} / \mathrm{d} v$. LC $113($ sem 16) $\mathrm{mg} / \mathrm{d}) \mathrm{Ca}$ excretion was significantly higher during the HC diet periods compared with the LC diet periods.
Faecal excretion of total fat, energy, bile acids, faecal weight (wet and dry) and transit time are presented in Table 4. Total faecal fat excretion was increased by increased dairy Ca intake (adjusted mean: LC $5.87 \mathrm{~g} / \mathrm{d} \quad v$. HC $8.34 \mathrm{~g} / \mathrm{d}$; $P<0 \cdot 0001)$ and increased dairy fat intake (adjusted mean: LF $6.47 \mathrm{~g} / \mathrm{d} v$. HF $8.35 \mathrm{~g} / \mathrm{d} ; P=0.0052)$. Faecal energy excretion (adjusted mean: LC $629 \mathrm{~kJ} / \mathrm{d} v$. HC $802 \mathrm{~kJ} / \mathrm{d} ; P=0.0003$ ) and bile acid excretion (adjusted mean: LC $203 \mu \mathrm{mol} / \mathrm{d} v$. HC $316 \mu \mathrm{mol} / \mathrm{d} ; P=0.0041)$ were increased by increased dairy Ca intake but not increased by dairy fat intake.

\section{Discussion}

The present study examined the short-term effects of high $v$. low dietary $\mathrm{Ca}$ intakes, in combination with $\mathrm{HF}$ and $\mathrm{LF}$ isoenergetic diets, on the lipid profile and faecal excretion of fat and bile acids. The major finding is that dairy Ca attenuates the increase in total and LDL-cholesterol produced by increased dairy fat, without affecting the rise in HDL-cholesterol. This is probably, at least in part, due to an increased faecal excretion of fatty acids and bile acid

Table 3. Faecal and urine excretion of calcium in the four diet periods

(Mean values with their standard errors)

\begin{tabular}{|c|c|c|c|c|c|c|c|c|c|c|c|}
\hline & \multicolumn{2}{|c|}{$\mathrm{LC} / \mathrm{HF}^{*}$} & \multicolumn{2}{|c|}{$\mathrm{HC} / \mathrm{HF}^{*}$} & \multicolumn{2}{|c|}{ LC/LF* } & \multicolumn{2}{|c|}{$\mathrm{HC} / \mathrm{LF} \dagger$} & \multicolumn{3}{|c|}{ Two-way ANOVA } \\
\hline & Mean & SEM & Mean & SEM & Mean & SEM & Mean & SEM & Dairy $\mathrm{Ca}$ & Dairy fat & Dairy $\mathrm{Ca} \times$ dairy fat \\
\hline Faecal Ca excretion $\ddagger$ (mg/d) & 549 & 34 & 2477 & 260 & 576 & 80 & 2478 & 163 & $<0.0001$ & 0.9832 & - \\
\hline Urine Ca excretion $(\mathrm{mg} / \mathrm{d})$ & 120 & 17 & 151 & 22 & 106 & 17 & 127 & 19 & 0.0089 & 0.0538 & - \\
\hline Total Ca excretion $\ddagger$ (mg/d) & 667 & 25 & 2628 & 251 & 678 & 74 & 2598 & 155 & $<0.0001$ & 0.9079 & - \\
\hline Total Ca excretion (\% of intake) & 97 & 4 & 92 & 6 & 93 & 9 & 91 & 7 & 0.5620 & 0.7019 & - \\
\hline
\end{tabular}

LC/HF, low Ca and high fat; HC/HF, high Ca and high fat; LC/LF, low Ca and low fat and HC/LF, high Ca and low fat.

${ }^{\star} n 8$.

$+n 7$.

$\ddagger$ Log-transformed before statistical analysis. 


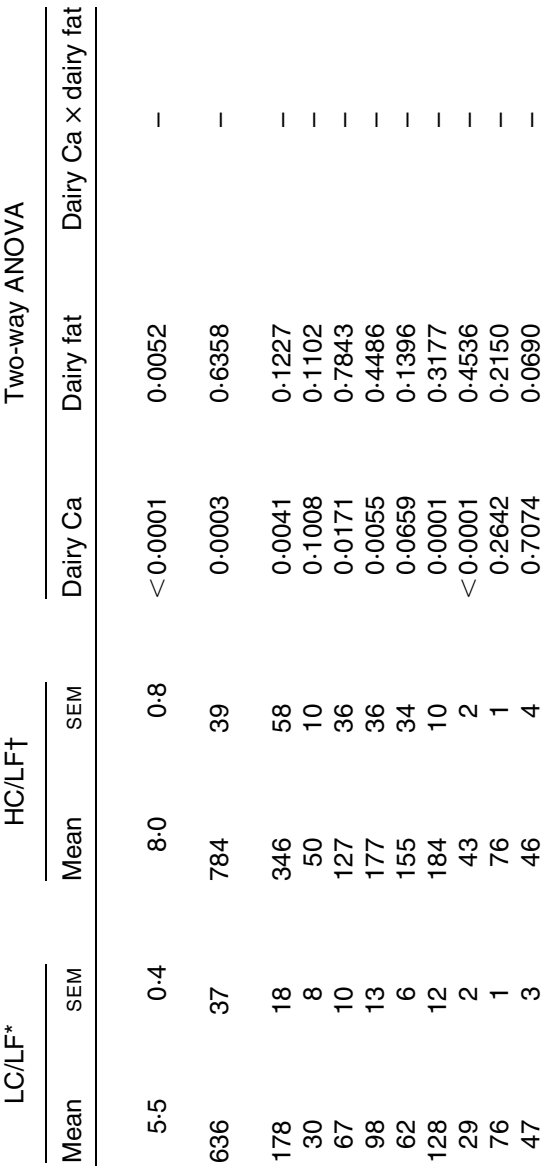

excretion, and possibly also increased excretion of other hydrophobic components, including cholesterol. However, other unidentified mechanisms may also be involved.

High concentrations of total and LDL-cholesterol are strong predictors of the risk of CVD. In contrast, high-HDL concentration has been associated with a protective effect on CVD. However, some doubt remains as to HDL being a marker or an actor, and it seems that the ratio of total:HDL-cholesterol or LDL:HDL-cholesterol is a better risk marker for CVD than HDL concentration in itself ${ }^{(44,45)}$. It is well accepted that dairy fat increases plasma cholesterol levels, due to its high concentration of SFA, especially palmitic acid ${ }^{(27)}$. However, data on the effect of dairy products are conflicting, as discussed in several reviews ${ }^{(29-31)}$.

In the present study, we found, as expected, that an increased intake of dairy fat produced an increase in LDLcholesterol. However, this increase was partly counteracted when dairy $\mathrm{Ca}$ intake was increased as well. Similar effects were found on total cholesterol concentration. The increase in dairy fat also produced an increase in HDL-cholesterol concentration. However, this increase was unaffected by the intake of dairy $\mathrm{Ca}$. We have previously shown a beneficial effect of dairy $\mathrm{Ca}$ on postprandial lipid metabolism ${ }^{(46)}$. An inverse association between dairy intake and risk of CVD has recently been reported ${ }^{(28)}$. Our data suggest that dairy Ca has a beneficial effect on blood lipids, which may, at least partly, explain this inverse association. In contrast to the beneficial effect of dairy products on CVD, Ca supplements (without co-administered vitamin D) have recently been shown to be associated with an increased risk of myocardial infarction ${ }^{(47)}$. The authors have suggested that the increased risk is due to an increase in serum Ca produced by the supplements, and that, as it has been shown that $\mathrm{Ca}$ from dairy products has a much smaller effect on serum $\mathrm{Ca}$ levels than $\mathrm{Ca}$ supplements, this could explain why supplementary but not dairy $\mathrm{Ca}$ increased the risk of myocardial infarction. We did not measure serum Ca concentrations in the present study. It is recommended that future studies also address this topic.

We found a significantly higher faecal fat excretion during the HC diet periods compared with the LC diet periods. This is in line with our previous studies examining the effect of dairy $\mathrm{Ca}$ on faecal fat excretion ${ }^{(23)}$, although the effect found in the present study is somewhat smaller than the effect that we have found previously ${ }^{(21,22)}$. Fat absorption is normally a very efficient process, which was observed in the present study, as the quantity of fat excreted during the two LC diet periods was very similar despite a large difference in fat intake (Table 4). It is therefore remarkable that $\mathrm{Ca}$ interferes with this process. The interference is most probably due to the formation of insoluble $\mathrm{Ca}$-fatty acid soaps and/or the formation of hydrophobe aggregations with phosphor and bile acids, and with other hydrophobe components including fatty acids ${ }^{(48-51)}$. It has been suggested that it is mostly SFA that interferes with $\mathrm{Ca}^{(24-26)}$. There are several possible explanations for the somewhat lower effect of the increased dairy $\mathrm{Ca}$ intake on faecal fat excretion found in the present study compared with our previous studies. First, it may 
be due to the source of dairy products used in the studies. In previous studies, we used a mixture of dairy products, mainly cheese and yogurt, and only relatively small amounts of milk, whereas milk alone was used in the present study. The concentration of both $\mathrm{Ca}$ and fat is about seven times lower in milk than in cheese. Furthermore, fat is present as small droplets enclosed by a membrane in milk ${ }^{(52)}$, whereas it is encapsulated by a protein structure in yogurt and is partly encapsulated in cheese (fat structure depends somewhat on the type of cheese). As part of the Ca will be bound to the milk proteins, especially casein, there may be a higher interaction between fat and $\mathrm{Ca}$ in yogurt and cheese than in milk, which may stimulate the formation of Ca-fatty acids in the intestine. Furthermore, it is possible that some $\mathrm{Ca}$-fatty acid soaps are formed during the production of yogurt in particular (due to homogenisation), but also in cheese; although most of these soaps would be dissolved at gastric $\mathrm{pH}$, it is possible that some of them will enter the duodenum as $\mathrm{Ca}$-fatty acid soaps and precipitate. Further studies are needed to examine this. Second, for Ca to interact with fat, it must be present in the duodenum at the same time as fat. In milk, $\mathrm{Ca}$ is in an aqueous phase, and in the present study (especially in the LF diet periods), a large part of the fat was in the solid part of the diet. Several studies have shown that the gastric emptying rate is faster for the aqueous phase of a meal than for the solid phase ${ }^{(53,54)}$. Thus, if milk and solid food were not mixed properly during ingestion, Ca will presumably have entered the duodenum before the majority of the fat from the diet, which will have resulted in limited possibilities for an interaction between $\mathrm{Ca}$ and fat to occur. This emphasises that the time of ingestion and the matrix in which $\mathrm{Ca}$ is provided are critical for the effect of $\mathrm{Ca}$ on fat digestibility. Third, milk has a high content of lactose, in contrast to cheese, and it has been suggested that lactose may bind phosphate ${ }^{(55)}$. As the first step in one of the suggested mechanisms by which Ca may affect fat digestibility is the formation of an amorphous complex with phosphate ${ }^{(51)}$, it is possible that high lactose content could, at least partly, have inhibited this formation and thereby affected the results. Fourth, it is possible that other bioactive components in cheese and/or yogurt may have acted either independently or synergistically with $\mathrm{Ca}$ to affect fat absorption.

Dairy Ca and, to a lesser extent, supplementary Ca have been shown to produce decreases in body weight and body fat in several studies ${ }^{(12-16)}$, but not in all studies ${ }^{(17-20)}$, and the size of the effect is uncertain. It is likely that at least part of the effect is due to the decreased fat absorption observed in the present study and other studies ${ }^{(21-23)}$. Other suggested mechanisms are beneficial effects on fat metabolism and appetite regulation ${ }^{(56,57)}$.

The cholesterol-lowering effect of dairy Ca observed in the present study can only partly be explained by the observed increased faecal fat excretion. According to Key's equation, a reduction in SFA of $4.7 \mathrm{~g} / \mathrm{d}$, corresponding to the difference between $\mathrm{HC} / \mathrm{HF}$ and $\mathrm{LC} / \mathrm{HF}$, would result in a reduction in the total cholesterol of $0 \cdot 12 \mathrm{mmol} / \mathrm{l}^{(58)}$, i.e. about a third of the effect observed in the present study. Assuming that SFA only account for a part of the increase in excreted fat, the reduction in cholesterol that can be attributed to the increased fat excretion is probably even lower. In agreement with us, others have found a cholesterol-reducing effect of Ca per se, which is larger than can directly be explained by the increased fat excretion ${ }^{(24,25)}$. Shahkhalili et al. ${ }^{(24)}$ showed, in a crossover study, that supplementation of chocolate with $0.9 \mathrm{wt} \%$ $\mathrm{Ca}$, as part of a diet providing 39\% of energy as fat, resulted in a twofold increase in total faecal fat excretion $(4.4-8.4 \mathrm{~g} / \mathrm{d})$ and a significantly higher decrease in LDL-cholesterol (0.43 (sem 0.39) v. $0.01(\operatorname{sem} 0.25) \mathrm{mmol} / \mathrm{l} ; P<0.02)$. This is somewhat similar to the present results. In a cross-over study, Denke et al. ${ }^{(25)}$ compared a control diet $34 \%$ of energy (E\%) fat) with a diet with a low content of $\mathrm{Ca}$ $(410 \mathrm{mg} / \mathrm{d})$ with a fortified version providing a total of $2200 \mathrm{mg} \mathrm{Ca}$, and found that faecal excretion of saturated fat, as related to intake, increased from 6 to $13 \%$. In addition, they found that LDL-cholesterol was $11 \%$ lower after the high $\mathrm{Ca}$ period compared with the low $\mathrm{Ca}$ period (3.67 (sem 0.49) v. 4.13 (SEM 0.54$) \mathrm{mmol} / \mathrm{l} ; \quad P<0.05)^{(25)}$ In both studies, increased faecal fat excretion is insufficient to explain the observed effect on LDL-cholesterol. It has therefore been suggested that $\mathrm{Ca}$ has an additional cholesterol-lowering effect, which may be due to the interaction with bile acids ${ }^{(25)}$. Increased $\mathrm{Ca}$ intake has been found to produce an increased faecal excretion of bile acids in both human $^{(59)}$ and animal ${ }^{(60)}$ studies. Decreased bile acid recycling through the enterohepatic circulation may result in increased cholesterol uptake from the circulation into the liver for the de novo synthesis of bile acids. Malabsorption of bile acids has been shown to produce a decrease in LDLcholesterol concentration presumably via a stimulation of the hepatic LDL receptor leading to an increased catabolic rate of LDL-cholesterol ${ }^{(61)}$. It has also been suggested that faecal fat excretion may be a poor estimate of fat absorption due to the subsequent degradation of unabsorbed fatty acids by the gut bacteria, and that the true effect of Ca may be underestimated by this method ${ }^{(25)}$. Furthermore, it cannot be excluded that other unidentified mechanisms may be involved. Future studies are needed to examine this. Finally, it is possible that other bioactive components in dairy products affect cholesterol concentrations.

The study had some limitations. Although all efforts were exerted to make the four diets as similar as possible, except for $\mathrm{Ca}$ and fat content, there were some differences in the compositions of the diets, and we cannot rule out that these differences may have confounded the outcome. Another criticism of the study is the short duration of the intervention period. However, with regard to the cholesterol concentration, the half-life of LDL-cholesterol is approximately $3 \mathrm{~d}$, and therefore $10 \mathrm{~d}$ ought to be sufficient for the majority of the effect on LDL-cholesterol to occur ${ }^{(62)}$. We cannot exclude the possibility that an adaptation to a long-term high $\mathrm{Ca}$ intake may occur, which could reduce the effect on both cholesterol concentration and faecal fat excretion. Further long-term studies are necessary to establish this. Finally, the dropout rate during the study was higher than anticipated, mainly due to the very demanding protocol. As described earlier, our intention was to include enough subjects to provide the power necessary to 
detect a difference in faecal total fat excretion of at least $4 \mathrm{~g} / \mathrm{d}$. One would expect the large dropout rate to affect the power of the study, but a post hoc power calculation showed that we actually had over $90 \%$ power to detect a difference in the faecal fat excretion of minimum $4 \mathrm{~g} / \mathrm{d}$. To fully understand the effects of dairy $\mathrm{Ca}$ on the lipid profile, larger studies are necessary.

The findings of the present study indicate that dairy Ca may partly counteract the raising effect of dairy fat on total and LDL-cholesterol, without reducing HDL-cholesterol.

\section{Acknowledgements}

We are grateful to the laboratory and kitchen staff, especially Elisabet Steinthorsdottir, Charlotte Kostecki and Yvonne Rasmussen, for their assistance. The study was financed by the Danish Dairy Board, Aarhus, Denmark, the Directorate for Food, Fisheries and Agri Business, the Danish Ministry of Food, Agriculture and Fisheries, Copenhagen, Denmark. The study was a part of a PhD project, which was financed by FOOD Graduate School, Arla Foods AmbA and Faculty of Life Science, University of Copenhagen. J. K. L. and A. A. designed the study. J. K. L. was responsible for collection of data and data analysis. Both authors participated in the discussion of the results and preparation of the manuscript. Potential conflicts of interest: A. A. is a member of Global Dairy Platform, Chicago, and receives an honorarium for each board meeting.

\section{References}

1. Pereira MA, Jacobs DR, Van Horn L, et al. (2002) Dairy consumption, obesity, and the insulin resistance syndrome in young adults: the CARDIA Study. JAMA 287, 2081-2089.

2. Elwood PC, Pickering JE, Fehily AM, et al. (2007) Milk and dairy consumption, diabetes and the metabolic syndrome: the Caerphilly prospective study. I Epidemiol Community Health 61, 695-698.

3. Brooks BM, Rajeshwari R, Nicklas TA, et al. (2006) Association of calcium intake, dairy product consumption with overweight status in young adults (1995-1996): the Bogalusa Heart Study. J Am Coll Nutr 25, 523-532.

4. Davies KM, Heaney RP, Recker RR, et al. (2000) Calcium intake and body weight. J Clin Endocrinol Metab 85, 4635-4638.

5. Jacqmain M, Doucet E, Després JP, et al. (2003) Calcium intake, body composition, and lipoprotein-lipid concentrations in adults. Am J Clin Nutr 77, 1448-1452.

6. Lin YC, Lyle RM, McCabe LD, et al. (2000) Dairy calcium is related to changes in body composition during a two-year exercise intervention in young women. $J$ Am Coll Nutr 19, $754-760$.

7. Loos RJ, Rankinen T, Leon AS, et al. (2004) Calcium intake is associated with adiposity in Black and White men and White women of the HERITAGE Family Study. J Nutr 134, $1772-1778$.

8. Lorenzen JK, Molgaard C, Michaelsen KF, et al. (2006) Calcium supplementation for $1 \mathrm{y}$ does not reduce body weight or fat mass in young girls. Am J Clin Nutr 83, 18-23.

9. Rosell M, Johansson G, Berglund L, et al. (2004) Associations between the intake of dairy fat and calcium and abdominal obesity. Int J Obes Relat Metab Disord 28, 1427-1434.
10. Shahar DR, Abel R, Elhayany A, et al. (2007) Does dairy calcium intake enhance weight loss among overweight diabetic patients? Diabetes Care 30, 485-489.

11. Zemel MB, Shi H, Greer B, et al. (2000) Regulation of adiposity by dietary calcium. FASEB J 14, 1132-1138.

12. Caan B, Neuhouser M, Aragaki A, et al. (2007) Calcium plus vitamin D supplementation and the risk of postmenopausal weight gain. Arch Intern Med 167, 893-902.

13. Eagan MS, Lyle RM, Gunther CW, et al. (2006) Effect of 1 -year dairy product intervention on fat mass in young women: 6-month follow-up. Obesity (Silver Spring) 14, $2242-2248$.

14. Zemel MB, Thompson W, Milstead A, et al. (2004) Calcium and dairy acceleration of weight and fat loss during energy restriction in obese adults. Obes Res 12, 582-590.

15. Zemel MB, Richards J, Milstead A, et al. (2005) Effects of calcium and dairy on body composition and weight loss in African-American adults. Obes Res 13, 1218-1225.

16. Zemel MB, Richards J, Mathis S, et al. (2005) Dairy augmentation of total and central fat loss in obese subjects. Int J Obes Relat Metab Disord 29, 391-397.

17. Winzenberg T, Shaw K, Fryer J, et al. (2007) Calcium supplements in healthy children do not affect weight gain, height, or body composition. Obesity (Silver Spring) 15, 1789-1798.

18. Trowman R, Dumville JC, Hahn S, et al. (2006) A systematic review of the effects of calcium supplementation on body weight. BrJ Nutr 95, 1033-1038.

19. Thompson WG, Rostad HN, Janzow DJ, et al. (2005) Effect of energy-reduced diets high in dairy products and fiber on weight loss in obese adults. Obes Res 13, 1344-1353.

20. Bowen J, Noakes M, Clifton PM, et al. (2005) Effect of calcium and dairy foods in high protein, energy-restricted diets on weight loss and metabolic parameters in overweight adults. Int J Obes (Lond) 29, 957-965.

21. Bendsen NT, Hother AL, Jensen SK, et al. (2008) Effect of dairy calcium on fecal fat excretion: a randomized crossover trial. Int J Obes (Lond) 32, 1816-1824.

22. Jacobsen R, Lorenzen JK, Toubro S, et al. (2005) Effect of short-term high dietary calcium intake on 24-h energy expenditure, fat oxidation, and fecal fat excretion. Int $J$ Obes (Lond) 29, 292-301.

23. Christensen R, Lorenzen JK, Svith CR, et al. (2009) Effect of calcium from dairy and dietary supplements on faecal fat excretion: a meta-analysis of randomised controlled trials. Obes Rev 10, 475-486.

24. Shahkhalili Y, Murset C, Meirim I, et al. (2001) Calcium supplementation of chocolate: effect on cocoa butter digestibility and blood lipids in humans. Am J Clin Nutr 73, 246-252.

25. Denke MA, Fox MM, Schulte MC, et al. (1993) Short-term dietary calcium fortification increases fecal saturated fat content and reduces serum lipids in men. J Nutr 123, 1047-1053.

26. Bhattacharyya AK, Thera C, Anderson JT, et al. (1969) Dietary calcium and fat. Effect on serum lipids and fecal excretion of cholesterol and its degradation products in man. Am J Clin Nutr 22, 1161-1174.

27. Grundy SM \& Denke MA (1990) Dietary influences on serum lipids and lipoproteins. J Lipid Res 31, 1149-1172.

28. Elwood PC, Pickering JE, Givens DI, et al. (2010) The consumption of milk and dairy foods and the incidence of vascular disease and diabetes: an overview of the evidence. Lipids 45, 925-939. 
29. Pfeuffer M \& Schrezenmeir J (2000) Bioactive substances in milk with properties decreasing risk of cardiovascular diseases. Br J Nutr 84, Suppl. 1, S155-S159.

30. Tholstrup $\mathrm{T}$ (2006) Dairy products and cardiovascular disease. Curr Opin Lipidol 17, 1-10.

31. Nestel PJ (2008) Effects of dairy fats within different foods on plasma lipids. J Am Coll Nutr 27, 735S-740S.

32. Reid IR (2004) Effects of calcium supplementation on circulating lipids: potential pharmacoeconomic implications. Drugs Aging 21, 7-17.

33. Reid IR, Mason B, Horne A, et al. (2002) Effects of calcium supplementation on serum lipid concentrations in normal older women: a randomized controlled trial. Am J Med 112, 343-347.

34. Bostick RM, Fosdick L, Grandits GA, et al. (2000) Effect of calcium supplementation on serum cholesterol and blood pressure. A randomized, double-blind, placebo-controlled, clinical trial. Arch Fam Med 9, 31-38.

35. Major GC, Alarie F, Doré J, et al. (2007) Supplementation with calcium + vitamin $\mathrm{D}$ enhances the beneficial effect of weight loss on plasma lipid and lipoprotein concentrations. Am J Clin Nutr 85, 54-59.

36. Karanja N, Morris CD, Rufolo P, et al. (1994) Impact of increasing calcium in the diet on nutrient consumption, plasma lipids, and lipoproteins in humans. Am J Clin Nutr 59, 900-907.

37. Westerterp KR, Donkers JH, Fredrix EW, et al. (1995) Energy intake, physical activity and body weight: a simulation model. Br J Nutr 73, 337-347.

38. Nordic Nutrition Recommendations 2004 (2005) Integrating Nutrition and Physical Activity (Nord 2004:013). Copenhagen: Nordic Council of Ministers.

39. Bouchard C, Tremblay A, Leblanc C, et al. (1983) A method to assess energy expenditure in children and adults. $\mathrm{Am} \mathrm{J}$ Clin Nutr 37, 461-467.

40. Bligh EG \& Dyer WJ (1959) A rapid method of total lipid extraction and purification. Can J Med Sci 37, 911-917.

41. Dekker R, Van der Meer R, Olieman C, et al. (1991) Sensitive pulsed amperometric detection of free and conjugated bile acids in combination with gradient reversed-phase HPLC. Chromatographia 31, 549-553.

42. Knarreborg A, Engberg RM, Jensen SK, et al. (2002) Quantitative determination of bile salt hydrolase activity in bacteria isolated from the small intestine of chickens. Appl Environ Microbiol 68, 6425-6428.

43. Cummings JH, Jenkins DJ \& Wiggins HS (1976) Measurement of the mean transit time of dietary residue through the human gut. Gut 17, 210-218.

44. Castelli WP (1996) Lipids, risk factors and ischaemic heart disease. Atherosclerosis 124, S1-S9.

45. Fernandez ML \& Webb D (2008) The LDL to HDL cholesterol ratio as a valuable tool to evaluate coronary heart disease risk. J Am Coll Nutr 27, 1-5.
46. Lorenzen JK, Nielsen S, Holst JJ, et al. (2007) Effect of dairy calcium or supplementary calcium intake on postprandial fat metabolism, appetite, and subsequent energy intake. Am J Clin Nutr 85, 678-687.

47. Bolland MJ, Avenell A, Baron JA, et al. (2010) Effect of calcium supplements on risk of myocardial infarction and cardiovascular events: meta-analysis. BMJ 341, c3691.

48. Gacs G \& Barltrop D (1977) Significance of Ca-soap formation for calcium absorption in the rat. Gut 18, 64-68.

49. Govers MJ, Termont DS, Van Aken GA, et al. (1994) Characterization of the adsorption of conjugated and unconjugated bile acids to insoluble, amorphous calcium phosphate. J Lipid Res 35, 741-748.

50. Patton JS \& Carey MC (1979) Watching fat digestion. Science 204, 145-148.

51. van der MR \& De Vries HT (1985) Differential binding of glycine- and taurine-conjugated bile acids to insoluble calcium phosphate. Biochem J 229, 265-268.

52. Hamosh M, Bitman J, Wood L, et al. (1985) Lipids in milk and the first steps in their digestion. Pediatrics $\mathbf{7 5}$, $146-150$.

53. Meyer JH, Mayer EA, Jehn D, et al. (1986) Gastric processing and emptying of fat. Gastroenterology 90, 1176-1187.

54. Cortot A, Phillips SF, Malagelada JR, et al. (1981) Gastric emptying of lipids after ingestion of a solid-liquid meal in humans. Gastroenterology 80, 922-927.

55. Gueguen L \& Pointillart A (2000) The bioavailability of dietary calcium. J Am Coll Nutr 19, 119S-136S.

56. Zemel MB (2003) Role of dietary calcium and dairy products in modulating adiposity. Lipids 38, 139-146.

57. Major GC, Alarie FP, Doré J, et al. (2009) Calcium plus vitamin D supplementation and fat mass loss in female very low-calcium consumers: potential link with a calciumspecific appetite control. Br J Nutr 101, 659-663.

58. Fetcher ES, Foster N, Anderson JT, et al. (1967) Quantitative estimation of diets to control serum cholesterol. Am J Clin Nutr 20, 475-492.

59. Govers MJ \& van der MR (1993) Effects of dietary calcium and phosphate on the intestinal interactions between calcium, phosphate, fatty acids, and bile acids. Gut $\mathbf{3 4}$, 365-370.

60. Govers MJ, Termont DS, Lapré JA, et al. (1996) Calcium in milk products precipitates intestinal fatty acids and secondary bile acids and thus inhibits colonic cytotoxicity in humans. Cancer Res 56, 3270-3275.

61. Farkkila M \& Miettinen TA (1900) Lipid metabolism in bile acid malabsorption. Ann Med 22, 5-13.

62. Langer T, Strober W \& Levy RI (1972) The metabolism of low density lipoprotein in familial type II hyperlipoproteinemia. J Clin Invest 51, 1528-1536. 